\title{
Feto-maternal outcomes in near miss events in obstetrics
}

\author{
Apoorva Kamboj, Kavita Mandrelle* \\ Department of Obstetrics and Gynaecology, Christian Medical College and Hospital, Ludhiana, Punjab, India
}

Received: 26 October 2021

Revised: 28 November 2021

Accepted: 29 November 2021

\author{
*Correspondence: \\ Dr. Kavita Mandrelle, \\ E-mail: kavitamandrelle@gmail.com
}

Copyright: () the author(s), publisher and licensee Medip Academy. This is an open-access article distributed under the terms of the Creative Commons Attribution Non-Commercial License, which permits unrestricted non-commercial use, distribution, and reproduction in any medium, provided the original work is properly cited.

\begin{abstract}
Background: Maternal near miss is defined by world health organization as a woman, who being close to death survives a complication occurring during pregnancy, delivery or upto 42 days after her end of pregnancy. It is a retrospective diagnosis. Evaluation of near miss maternal morbidity and mortality is a surveillance method to assess the quality of obstetric care and determinants of poor maternal outcome. It is an indicator of quality of obstetrical care. Aims and objectives for current study was to evaluate the cause of near miss maternal morbidity in our hospital which occurred either in admitted patients or were referred from elsewhere and to study the maternal and fetal outcomes in all near miss cases.

Methods: A retrospective review of obstetrical records as well as prospective analysis was done at Christian medical college and hospital, a tertiary care teaching institute in North India and referral centre. The study was done for a period of one year from November 2018 to October 2019 retrospectively and for 6 months from November 2019 to April 2020 prospectively. The maternal near miss cases were taken as per WHO criteria.

Results: The age ranged from 19 years to 49 years with maximum belonging to age group of 20-24 years. Maximum number of cases was primigravida and was in third trimester. The primary obstetric complication evaluated were hypertensive disorders followed by hematological diseases, viral hepatitis, haemorrhage, and obstructed labour or ruptured uterus.

Conclusions: All the causes of MNM observed in this study are preventable causes, which can be identified timely and treated early to prevent maternal mortality, thereby, improving obstetrical and neonatal outcome.
\end{abstract}

Keywords: Near miss events in obstetrics, Feto- maternal outcomes

\section{INTRODUCTION}

Maternal "near miss" is defined by WHO as a woman, who being close to death survives a complication occurring during pregnancy, delivery or up to 42 days after her end of pregnancy. Maternal near miss (MNM) events are life threatening obstetric complications requiring urgent medical intervention in order to prevent the evident maternal mortality. Maternal mortality is a health indicator over the world which is depicted by maternal mortality ratio (MMR). MMR is defined as ratio of number of maternal deaths per 1 lakh live births. ${ }^{1,2}$
Evaluation of "near miss" maternal mortality is a surveillance method to assess the quality of obstetric care and determinants of poor maternal outcome. It is a retrospective diagnosis. It is helpful in identifying the failures, lacunae and positive elements in providing good quality of health care. Thus, it being an indicator of quality of obstetrical care acts as a mirror to show the main causes of maternal mortality thereby providing with an opportunity to improve the quality of health care by timely intervention to put a stop to the causative factors at the first stage itself. ${ }^{3,4}$ Reduction in maternal mortality is one of the targets of millennium development goals 
(MDG) for 2015 but in spite of efforts high maternal morbidity and mortality remains a major challenge in developing countries. ${ }^{5}$ Modern obstetrics is concerned with the health and well being of both the mother as well as the fetus. Hence interest has grown in using these near miss events as a guiding pathway for providing the utmost quality of obstetrical care so as to achieve the primary goal of providing safe motherhood.

\section{Aim and objectives}

The objectives of this study were to evaluate the cause of near miss maternal morbidity in our hospital which occurred either in admitted patients or were referred from elsewhere and to study the maternal and fetal outcomes in all near miss cases.

\section{METHODS}

A retrospective review of obstetrical record as well as prospective analysis was done in department of obstetrics and gynaecology at Christian medical college and hospital, Ludhiana, a tertiary care teaching institute in North India and referral centre. The study included study cases for a period of one year from November 2018 to October 2019 retrospectively and for 6 months from November 2019 to April 2020 prospectively. Total of 90 Maternal Near Miss cases were taken over duration of 18 months as per WHO criteria. All pregnant women admitted for delivery, or within 42 days of delivery or termination of pregnancy, booked at our hospital or referred from elsewhere who fit into the criteria of WHO MNM were included in the study. Pregnant ladies who did not fit into the WHO MNM criteria or had maternal mortality were excluded from this study.

\section{Statistical analysis}

The data was entered into Microsoft excel sheet. All statistical analysis was performed using SPSS (statistical packages for social sciences, version 21.0. Armonk, NY: IBM corp.)

\section{WHO criteria for maternal near miss}

Clinical criteria: acute cyanosis, gasping which is terminal respiratory pattern and breath is convulsively and audibly caught, respiratory rate $>40$ or $<6 / \mathrm{min}$, Shock which is a persistent severe hypotension defined as a systolic $\mathrm{BP}<90 \mathrm{~mm} \mathrm{Hg}$ for $>60$ minutes with a pulse rate of at least $120 / \mathrm{min}$ despite aggressive fluid replacement (>21), oligurianon responsive to fluids or diuretics; oliguria is defined as urine output $<30 \mathrm{ml} / \mathrm{hr}$ for $4 \mathrm{hrs}$ or $<400 \mathrm{ml} / 24 \mathrm{hrs}$, clotting failure; clotting failure can be assessed by the bedside clotting test or the absence of clotting from IV site after 7-10 minutes, loss of consciousness >12 hours; loss of consciousness is profound alteration of mental state that involves complete or near complete, loss of consciousness and the absence of pulse/ heart beat, stroke; stroke is a neurological deficit of cardiovascular cause that persists beyond 24 hours or is interrupted by death within 24 hours, uncontrollable fits/paralysis; condition in which the brain is in a state of continuous seizure, jaundice in the presence of pre eclampsia, pre-eclampsia is defined as the presence of hypertension associated with proteinuria. Hypertension is defined as BP of at least $140 \mathrm{mmHg}$ (systolic) or at least $90 \mathrm{mmHg}$ (diastolic) on at least 2 occasions and at least 4-6 hours apart after $20^{\text {th }}$ week of gestation in women known to be normotensive beforehand. Proteinuria is defined as excretion of $\geq 300 \mathrm{mg}$ protein every 24 hours.

Laboratory based criteria: oxygen saturation $<90 \%$ for $>60$ minutes, $\mathrm{pH}<7.1, \mathrm{PaO} 2 / \mathrm{FiO} 2<200 \mathrm{mmHg}$, creatinine $>300 \mathrm{mmol} / \mathrm{l}$ or $>3.5 \mathrm{mg} / \mathrm{l}$, acute thrombocytopenia (platelets $<50,000$ ), bilirubin $>100$ $\mathrm{mmol} / \mathrm{l}$ or $6 \mathrm{mg} / \mathrm{dl}$ and loss of consciousness and the presence of glucose and ketoacids in urine.

Management based criteria: use of continuous drugs; Continuous use of any dose of dopamine, epinephrine or norepinephrine, intubation and ventilation for $>60 \mathrm{~min}$ not related to anesthesia, hysterectomy following infection or hemorrhage, dialysis for acute renal failure and transfusion of $\geq 5$ units of blood and cardiopulmonary resuscitation.

\section{RESULTS}

All the cases which fit into WHO MNM criteria were taken into the study and were followed till discharge from the hospital. The age ranged from 19 years to 49 years with maximum belonging to age group of 20-24 years (42.2\%) (Figure 1).

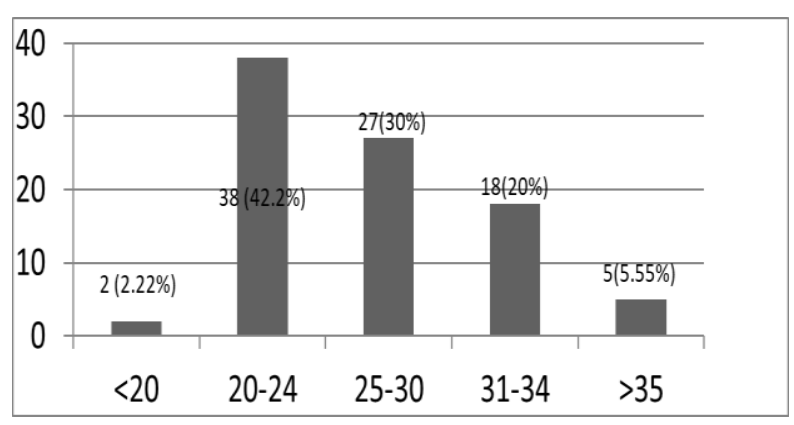

Figure 1: Distribution of study cases according to age.

Majority of cases were primigravida (51\%), out of which the maximum cases belong to gestation of 28-40weeks $(75.5 \%)$ (Figure 2). The number of booked cases was $25.5 \%$ and unbooked cases were $74.5 \%$. Majority of the cases $(94.4 \%)$ were discharged from the patient in less than seven days. A total of 80 patients $(89.9 \%)$ cases delivered at CMC, hospital out of which 43(48\%) were lower segment caesarean section (LSCS) and 37 (41\%) vaginal deliveries. One case was at $7+6$ weeks who had missed abortion and it fit into the criteria of WHO MNM as she had viral hepatitis. Nine patients were delivered 
outside out of which seven were delivered vaginally and two had undergone LSCS.

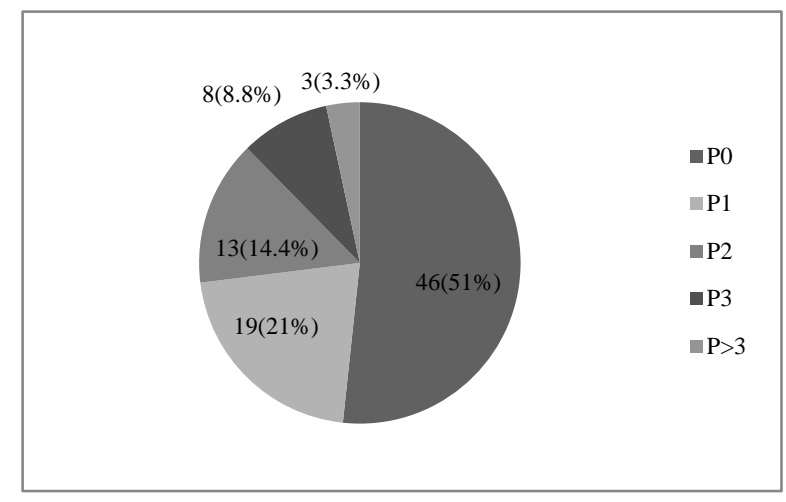

Figure 2: Study cases as per parity.

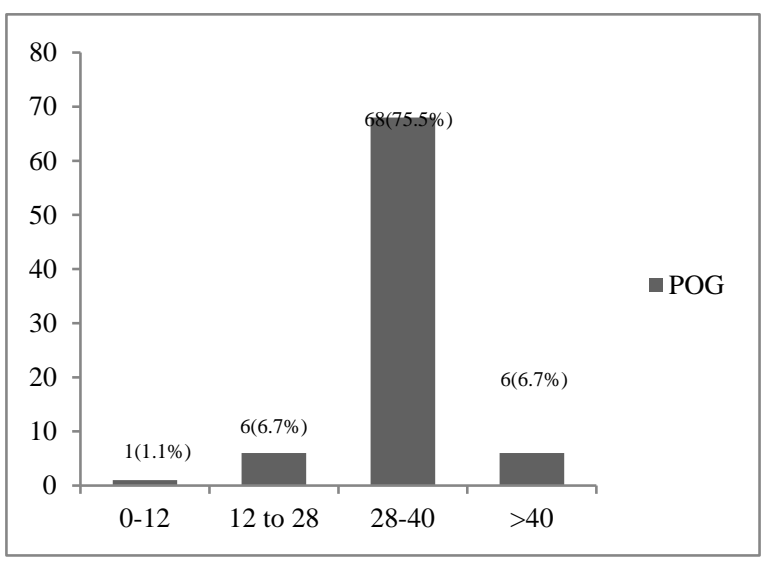

Figure 3: Study cases as per period of gestation. $2.2 \%$ cases were post operative and $7.8 \%$ cases were postpartum.



Figure 4: Fetal outcomes as per weight of fetus according to gestational age.

\section{Distribution of cases according to WHO criteria}

Total $37.8 \%$ cases required intensive care unit (ICU) care. $58.9 \%$ cases required operative intervention (Table 2).

\section{Distribution of maternal near miss cases according to primary obstetric complication affecting pregnancy}

Total $91.1 \%$ of cases recovered, $7.8 \%$ left against medical advice and $1.1 \%$ had residual morbidity (only 1 case had neurological changes in her magnetic resonance imaging (MRI) brain for which she was transferred over to neurology) (Table 3).

Table 2: Distribution of study cases according to WHO criteria.

\begin{tabular}{|c|c|c|}
\hline $\begin{array}{l}\text { Clinical } \\
\text { criteria (N) }\end{array}$ & $\begin{array}{l}\text { Laboratory } \\
\text { based criteria } \\
\text { (N) }\end{array}$ & $\begin{array}{l}\text { Management } \\
\text { based criteria } \\
(\mathrm{N})\end{array}$ \\
\hline Shock (13) & \multirow{3}{*}{$\begin{array}{l}\text { Creatinine } \\
>3.5 \mathrm{mg} / \mathrm{dl}(2)\end{array}$} & Use of \\
\hline \multirow{3}{*}{$\begin{array}{l}\text { Uncontrolled } \\
\text { fits (10) }\end{array}$} & & $\begin{array}{l}\text { continuous } \\
\text { drugs (32) }\end{array}$ \\
\hline & & Intubation (31) \\
\hline & \multirow{2}{*}{$\begin{array}{l}\text { Acute } \\
\text { thrombocytopenia } \\
(40)\end{array}$} & $\begin{array}{l}\text { Hysterectomy } \\
\text { (10) }\end{array}$ \\
\hline Gasping (3) & & Dialysis (2) \\
\hline $\begin{array}{l}\text { Cardiac } \\
\operatorname{arrest}(6)\end{array}$ & \multirow{3}{*}{$\begin{array}{l}\text { Bilirubin >6 } \\
\mathrm{mg} / \mathrm{dl}(18)\end{array}$} & $\begin{array}{l}\text { Cardiopulmonar } \\
\text { y resuscitation }\end{array}$ \\
\hline \multirow[b]{2}{*}{$\begin{array}{l}\text { Jaundice with } \\
\text { pre-eclampsia } \\
\text { (7) }\end{array}$} & & (5) \\
\hline & & $\begin{array}{l}\text { Blood } \\
\text { transfusion } \geq 5 \\
(23)\end{array}$ \\
\hline
\end{tabular}

\section{Fetal outcomes}

Total $80(89.9 \%)$ deliveries conducted at CMC, rest were delivered outside. $70(78.65 \%)$ were live born out of which $62(88.6 \%)$ were delivered in CMC. $5(8 \%)$ were neonatal deaths (NND). 17 (19.1\%) were fresh still births (FSB), and $2(2.2 \%)$ were Macerated still births (MSB).

Out of 23 booked cases, 21 were live born and 2 were still born, and out of 67 unbooked cases, 49 were live born and 17 were still born. 88.7\% (55 out of 62) required neonatal intensive care unit (NICU) admission out of which $38.1 \%$ (21 out of 55) were intubated, $33.3 \%$ (7 out of 21) requiring surfactant. 52 out of $62(84 \%)$ live borns in $\mathrm{CMC}$ were appropriate for gestational age (AGA), 5 (8\%) were small for gestational age (SGA) and large for gestational age (LGA) each (Figure 3). 17 (31\%) out of 55 newborns admitted in NICU had septicemia.

$7(12.7 \%)$ out of 55 newborns admitted in NICU had hypoxic ischaemic encephalopathy (HIE). 16 (25.8\%) out of total 62 live borns had congenital anomalies such as patent ductus arteriosus (PDA), extra nipple, poly-dactyly etc. $32(51.6 \%)$ of newborns had post-birth complications such as meconium aspiration syndrome (MAS), pulmonary haemorrhage, pulmonary hypertension, shock etc. $17(27.4 \%)$ of live births had birth asphyxia. Hospital stayed varied from 1 day to 49 days, with maximum (54\%) having duration of 3-7 days. 33 babies admitted in NICU recovered $(60 \%), 17$ left against medical advice (31\%), 5 out of 62 live births were NNDs (8\%). 


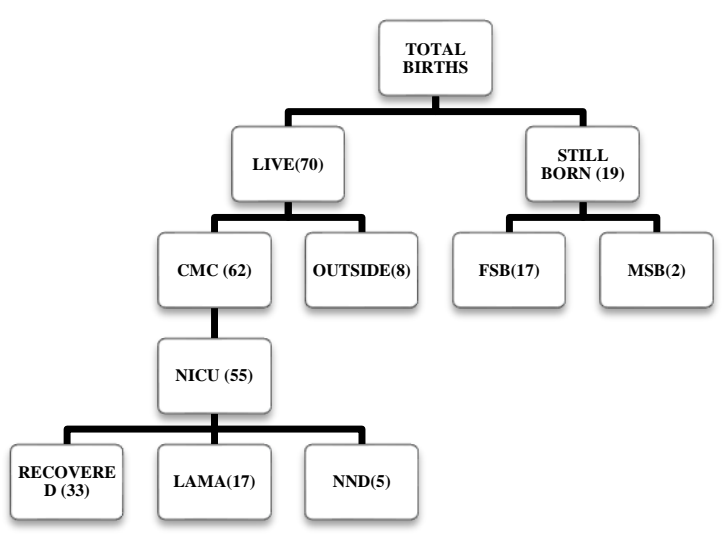

Figure 5: Fetal outcomes.

Table 3: Distribution of maternal near miss cases according to primary obstetric complication affecting pregnancy.

\begin{tabular}{|ll|}
\hline $\begin{array}{l}\text { Primary complication of } \\
\text { pregnancy }\end{array}$ & $\begin{array}{l}\text { Maternal near } \\
\text { miss N }(\%)\end{array}$ \\
\hline Ante-partum haemorrhage & $6(6.7)$ \\
\hline Post-partum haemorrhage & $6(6.7)$ \\
\hline $\begin{array}{l}\text { Hypertensive disorders of } \\
\text { pregnancy }\end{array}$ & $24(26.7)$ \\
\hline $\begin{array}{l}\text { Obstructed labour/ruptured } \\
\text { uterus }\end{array}$ & $12(13.3)$ \\
\hline Viral hepatitis & $19(21.1)$ \\
\hline Haematological disorders & $23(25.5)$ \\
\hline
\end{tabular}

\section{DISCUSSION}

The world health organization has proposed a package of 25 severity markers including clinical signs, laboratory tests and management parameters to address the need for a consensus criteria which can be used all over the world. Reduction in maternal mortality is one of the targets of Millennium Development Goals for 2015 but in spite of best efforts by all heath sectors it still remains a major challenge in developing nations. In this study, after identifying cases of maternal near miss according to WHO criteria, the primary obstetric complication was evaluated in each case. Like other studies conducted in Nepal and Ethiopia, majority of cases were in age group of 20-34 years of age. ${ }^{7,8}$ Maximum number of cases was primigravida, unlike previous studies. ${ }^{7-10} \mathrm{MNM}$ was more frequently seen in the third trimester, which is similar to other studies. ${ }^{7,8}$ Our being a tertiary referral center most of the cases were referred from nearby public and private sector hospitals, as was seen in other studies as well. ${ }^{8,11,12}$ Like other studies hypertensive disorders, hematological disorders and haemorrhage were the leading cause of MNM in our setting. ${ }^{13}$ In our study, viral hepatitis was also one of the leading causes of MNM, which was not seen in studies conducted earlier. We observed that obstetric delay may be due to low literacy, poor health seeking behavior, poor transportation facilities and poor decision making at family level which added to high
MNM at our facility. Most of the cases were unbooked and were referred in a critical state from other hospitals. The reason for MNM can be attributed to multiple factors such as lack of proper antenatal care, delay in primary obstetric care, mismanagement at the referral point and lapses in the referral chain. This study about fetomaternal outcomes in near miss cases tells us about the care and quality of health services provided by our institute, as majority of the patients recovered from morbid conditions and had no long term sequelae, thereby having a major role in preventing maternal mortality. Thus, the level of care provided by the hospital plays a big part in reducing the rate of maternal morbidity and mortality.

\section{Limitations}

Current study had limitations of having a small sample size and included retrospective data along with prospective cases. A prospective cohort study with a larger sample size will give a true picture of near miss events and strategies to prevent and reduce maternal morbidity.

\section{CONCLUSION}

Developing Nations and low resource setting countries like India carry high burden of maternal mortality and morbidity. Though institutional deliveries are on a rise but still there is lack of proper antenatal care, poor referral facilities, improper transport system, poor access/ utilization of health care services. All the above causes of MNM are preventable causes, which can be identified timely and treated early to prevent life threatening complications. Monitoring and surveillance of near miss morbidity and maternal mortality can identify preventive measures which can be timely intervened and hence improve obstetrical and neonatal outcome.

\section{Funding: No funding sources}

Conflict of interest: None declared

Ethical approval: The study was approved by the Institutional Ethics Committee

\section{REFERENCES}

1. Geller S, Rosenberg D, Cox S. Defining a conceptual framework for near miss maternal morbidity. J Am Med Women Assoc. 2002;57:135-9

2. Le Bacq F, Reitsema A. High maternal mortality levels and additional risks from poor accessibility in two districts of northern province, Zambia. Int J Epidemiol. 1997;26:357-63

3. Kaye DK, Kakaire O, Osinde MO. Systematic review of the magnitude and case fatality ratio for severe maternal morbidity in sub-Saharan Africa between 1995 and 2010. BMC Preg Childbirth. 2011;11:65

4. Adisasmita A, Deviany PE, Nandiaty F, Stanton C, Ronsmans C. Obstetric near miss and deaths in public 
and private hospitals in Indonesia. BMC Preg Childbirth. 2008;8:10

5. The Millennium Development Goals Report 2008. Available at: https://www.un.org/millenniumgoals/ 2008highlevel/pdf/newsroom/mdg\%20reports/MDG_ Report_2008_ENGLISH.pdf. Accessed on 25 September 2021.

6. Say L, Souza JP, Pattinson RC, WHO working group on maternal mortality and morbidity classifications: maternal near miss-towards a standard tool for monitoring quality of maternal health care. Best Pract Res Clin Obstet Gynaecol. 2009;23(3):287-96

7. Shrestha J, Shrestha R, Tuladhar R, Gurung S, Shrestha A. Maternal near miss in a tertiary care teaching hospital. Ame J Public Health Res. 2015; $3(5 \mathrm{~A}): 17-22$.

8. Gedefaw M, Gebrehana H, Gizac\$hew A, Taddess F. Assessment of maternal near miss at debremarkos referral hospital, Northwest Ethiopia: five years' experience. J Epidemiol. 2014;4:199-207.

9. Wianwiset W. Maternal near miss (severe morbidity) at Sisaket Hospital. J Obstet Gynecol. 2012;20:69-76.
10. Kabakyenga JK, Ostergren PO, Turyakira E, Mukasa $\mathrm{PM}$, Pettersson KO. Individual and health facility factors and the risk for obstructed labor and its adverse outcomes in South-Western Uganda. BMC Preg Childbirth. 2011;11:73.

11. Oladapo OT, Sule-Odu AO, Olatunji AO, Daniel OJ. Near-miss obstetric events and maternal deaths in Sagamu, Nigeria: a retrospective study. Reprod Health. 2005;2:1186-95.

12. Sikeder SS, Labrique AB, Ullah B, Ali H, Rashid M, Mehra S, et al. Accounts of severe acute obstetric complications in rural Bangladesh. BMC Preg Childbirth. 2011;11:76.

13. Olufemi T, Oladapo A. Near-miss obstetric events and maternal deaths in Sagamu, Nigeria: a retrospective study. Reprod Health. 2005;2:9.

Cite this article as: Kamboj A, Mandrelle K.

Feto-maternal outcomes in near miss events in obstetrics. Int J Reprod Contracept Obstet Gynecol 2022;11:172-6. 